\title{
The effectiveness of inpatient rehabilitation after uncomplicated total hip arthroplasty: a propensity score matched cohort
}

\author{
Justine M. Naylor ${ }^{1,2,3^{*}}$ D, Andrew Hart', Rajat Mittal ${ }^{1}$, lan A. Harris ${ }^{1,2,3}$ and Wei Xuan ${ }^{1,3}$
}

\begin{abstract}
Background: Inpatient rehabilitation is an expensive option following total hip arthroplasty (THA). We aimed to determine if THA patients who receive inpatient rehabilitation report better hip and quality of life scores postsurgery compared to those discharged directly home.
\end{abstract}

Methods: Prospective, propensity score matched cohort involving 12 private hospitals across five Australian States. Patients undergoing THA secondary to osteoarthritis were included. Those receiving inpatient rehabilitation for reasons other than choice or who experienced significant health events within 90-days post-surgery were excluded. Comparisons were made between those who did and did not receive inpatient rehabilitation for patient-reported hip pain and function (Oxford Hip Score, OHS) and 'today' health rating (EuroQol 0-100 scale). Rehabilitation provider charges were also estimated and compared.

Results: Two hundred forty-six patients (123 pairs, mean age 67 (10) yr., 66\% female) were matched on 19 covariates for their propensity to receive inpatient rehabilitation. No statistically nor clinically significant between-group differences were observed [OHS median difference (IQR): $0(-3,3), P=0.60 ; 0(-1$ to 1$), P=0.91$, at 90 and 365-days, respectively; EuroQol scale median difference $0(-10,12), P=0.24 ; 0(-10,10), P=0.49 ; 5(-10,15), P=0.09$, at 35-, 90and 365-days, respectively]. Median rehabilitation provider charges were 10-fold higher for those who received inpatient rehabilitation [median difference $\$ 7582(5649,10,249), P<0.001$ ]. Sensitivity analyses corroborated the results of the primary analyses.

Conclusion: Utilization of inpatient rehabilitation pathways following THA appears to be low value healthcare. Sustainability of inpatient rehabilitation models may be enhanced if inpatient rehabilitation is reserved for those most impaired or who have limited social supports.

Trial registration: ClinicalTrials.gov Identifier: NCT01899443.

Keywords: Arthroplasty, Arthroplasty, Hip, Rehabilitation, Physical therapy

\section{Background}

Total hip arthroplasty (THA) has been heralded as the 'operation of the Century' [1]. Large improvements in mobility and patient-reported outcomes are typically observed with changes far exceeding the small-to-moderate effects seen with non-surgical interventions for arthritis [2-4]. These changes are often experienced in the early

\footnotetext{
* Correspondence: Justine.Naylor@health.nsw.gov.au

${ }^{1}$ South Western Sydney Clinical School, University of New South Wales,

Liverpool Hospital, Elizabeth Drive, Liverpool, NSW 2170, Australia

${ }^{2}$ South West Sydney Local Health District, Locked Bag 7103, Liverpool, NSW

2170, Australia

Full list of author information is available at the end of the article
}

subacute phase and improvements are evident regardless of underlying aetiology $[3,5,6]$. Such is the success of the operation, annual increases in the volume of surgery in Australia - as it has elsewhere - have been recorded by the Australian Orthopaedic Association National Joint Replacement Registry (AOANJRR) since 2003 [7]. Presently, over 36,000 THA procedures are undertaken annually in Australia with the majority $(\sim 60 \%)$ performed in the private sector [7]. In 2016, 87,733 primary THA procedures were performed in the United Kingdom (UK) [8]. In the United States (US), it is estimated that up to 562,000 THA cases may be undertaken annually by 2030 [9]. 
Following surgery, physiotherapy-led exercise-based rehabilitation is often prescribed [10]. Evidence in support of such prescription is apparent when physiotherapy-led programs are compared to no or minimal intervention following THA. A recent systematic review of randomized trials concluded that physiotherapy-led exercise programs yielded better gait-related outcomes post-THA when compared to no intervention [10]. Interestingly, consistent with the evidence concerning the more intensive clinic-based rehabilitation programs following total knee arthroplasty (TKA) [11-15], clinic-based one-to-one or group-based programs have not been shown to be superior over monitored or unmonitored home-based programs for the recovery of mobility, function and health-related quality of life after THA $[10,16,17]$. Further, the evidence-base lacks randomized trials comparing inpatient-based rehabilitation with less intensive programs. This gap is important to address as utilization of inpatient rehabilitation is common and it is a comparatively costly pathway [18-20]. Recent Australian data from the private sector indicate the median referral rate per surgeon to inpatient rehabilitation is $29 \%$ (range $0-100 \%$ ) [21]. Inpatient utilization rates vary internationally [22, 23], with reported rates as high as $81 \%$ (Japan) and $53 \%$ (US) and as low as $0 \%$ (Spain, Turkey) and 3\% (UK) [24].

Only one randomized controlled trial (RCT) has been published aimed at determining the efficacy of inpatient therapy over a non-inpatient alternative following THA [25]. Eighteen days of inpatient rehabilitation was not more effective nor cost-effective compared to eigth domiciliary (physiotherapy) visits following THA or TKA (combined cohort).

Randomized trials are difficult to undertake in general, but they are particularly difficult to perform in the private healthcare sector where consumer and provider preferences are strong drivers of care delivery [26, 27]. This may partly explain why much of the evidence in this space - showing no superiority of the inpatient pathway - is predominantly provided by retrospective and prospective observational studies and administrative datasets [19, 28-30].

In light of the difficulty in performing an RCT, this study, using a propensity score (PS) matched cohort, aimed to determine whether privately insured THA patients who received inpatient rehabilitation, compared to those who did not, had better patient-reported joint and health scores across the first 12 months post-surgery. Informed by the high- and low-level evidence in this area, we hypothesized that the inpatient pathway would not procure superior patient-reported recovery to a level that was clinically meaningful over the alternative.

\section{Methods}

This study was nested within a national, prospective observational study involving 19 hospitals across five States
[31] (ClinicalTrials.gov Identifier: NCT01899443). We have previously reported the results of a related PS matched cohort aimed at determining the effectiveness of a rehabilitation pathway involving inpatient rehabilitation compared to one not involving inpatient rehabilitation following TKA [32]. The PS is the probability of treatment assignment conditional on observed baseline characteristics [33-38]. Here, matching people on their probability of being allocated to inpatient therapy addresses treatment selection bias based on known patient characteristics.

\section{Ethical approval and funding source}

Ethical approval was provided by multiple ethics committees (see Declarations). Informed participant consent was obtained. The HCF Research Foundation funded the study, but had no role in study design or data analysis.

\section{Sampling and hospital recruitment}

Hospitals contributing to the AOANJRR [7] performing over 275 TKA or THA procedures in 2012, were eligible to participate in the larger study. Related publications describe the sampling procedure which procured 10 public and nine private hospitals [31, 32, 39].

\section{Patient enrolment and eligibility}

Patient enrolment and eligibility were identical to that described in an aforementioned study [32]. People awaiting arthroplasty secondary to osteoarthritis between August 2013-December 2014 were screened by site coordinators during their pre-admission review. Eligibility criteria for the larger study included primary surgery, no further arthroplasty planned within 3-months, and the ability to understand the protocol and be followed-up by telephone for 1 year. For this nested study, being privately insured was an additional inclusion criterion. Publicly insured patients were explicitly excluded because the few referred to inpatient rehabilitation (20/317, $6.3 \%)$ were primarily referred based on a clinical or social need $(14 / 20)$. To reduce treatment selection bias and improve generalizability to uncomplicated THA, we also subsequently excluded the privately insured patients referred to inpatient rehabilitation due to slow progress, inadequate social supports (e.g living alone or without the help of an able carer), and those with conditions that would alter their rehabilitation pathway (e.g bilateral surgery or significant complication (defined below) up to 90-days post-surgery).

\section{Data collection}

Patient-level variables collected prior to surgery (baseline) included weight, height, insurance status, comorbid conditions including requirement for daily medication, education level, presence of other lower limb or back 
conditions impairing mobility and patient-reported outcomes measures (PROM). Additional patient-specific data via clinician-completed forms were collected by site coordinators - American Society of Anesthesiologists (ASA) scores, complications, length of stay (LOS), discharge destination, and reason for referral to inpatient rehabilitation if relevant. Patient-reported outcomes, including surveys, ongoing rehabilitation details, complication, and time-off-work (patient, carer) were obtained by researchers by telephone at 35, 90 and 365-days post-surgery. For quality control, clinician-collected data were re-abstracted from the medical record by researchers; significant patient-reported complications were verified by treating hospitals, surgeons or general practitioners.

\section{Complications}

Acute complications were stratified according to the Clavien-Dindo Classification whereby the code applied $(1-5)$ is based on the type of care deviation necessitated by the complication [40]. People experiencing the more severe complications (coded $\geq 3$ ) (e.g pulmonary emboli or dislocation), were excluded. Those experiencing a less severe complication, but one potentially affecting longer-term recovery (e.g neuropraxia) were also excluded. Patients experiencing any surgery-related complication requiring re-admission or any unrelated health event requiring hospital admission up to 90 days post-surgery, were also excluded.

\section{Outcomes}

The Oxford Hip Score (OHS) [41] and the Euroqol Visual Analogue Scale for health 'today' (EQVAS) [42, 43], were the primary outcomes. The EQVAS was obtained using a VAS at baseline and verbally at the time of follow-up as the methods have been shown to be equivalent in people awaiting arthroplasty [42].

Rehabilitation charges were determined from the perspective of the provider and the methodology is described elsewhere [32]. Table 1 summarizes the unit costs (AUD) applied for each rehabilitation 'type' encountered. Total provider charges for each participant were calculated based on the length of stay in a rehabilitation facility (where applicable), and the type and frequency of community-based therapy received up to 10-weeks post-surgery, including clinic, domiciliary, supervised hydrotherapy, and day hospital visits. Individuals in the 'No inpatient rehabilitation' group who also had no community-based rehabilitation were assigned $\$ 0$ rehabilitation provider charges.

\section{Analysis}

The projected sample size for the larger study was 2000. Assuming our recruitment pattern was consistent with patterns observed in the AOANJRR [7], we anticipated the definitive sample would comprise $40 \%$ THA recipients $(n=800)$, and most of those $(60 \%)(n=480)$ would be private insured. We conservatively predicted, therefore, our sample for this nested study would exceed 128 people (64 in each treatment group) which is what would be required ( $80 \%$ power, 0.05 significance level) to detect a minimal important between-group difference of 5 points ( 0.55 of the baseline SD) [41] in the OHS. A sample of 17 would be sufficient to detect a minimally clinically important improvement of 23 (1.36 SD [42, 43] baseline mean) for the EQVAS.

We assessed normality of the data prior to analysis. Mean, median and percentages were used to characterize the cohorts. Covariates of the unmatched cohorts were assessed using independent $t$-tests and $x^{2}$, whilst covariates and outcomes in the matched (paired) cohorts were assessed using paired t-tests, Wilcoxon signed-rank tests and McNemar tests [33, 34].

Propensity score determination and subsequent matching were determined as follows:

i) PSs for the prediction of referral to inpatient rehabilitation were estimated for all eligible patients using unconditional logistic regression [33-35]. Here, the outcome was treatment group and model covariates included variables thought to influence treatment assignment prior to surgery or the primary outcomes [33-35]. Covariates included baseline Oxford and EQVAS scores, age, body mass index (weight $[\mathrm{kg}] /$ height $[\mathrm{m}]^{2}$ ), gender, ASA scores,

Table 1 Unit charges assigned to each rehabilitation 'type' encountered

\begin{tabular}{|c|c|c|}
\hline Rehabilitation 'type' & Unit charge & Comments \\
\hline $\begin{array}{l}\text { Inpatient rehabilitation, } \\
\text { per night }\end{array}$ & $\$ 700$ & $\begin{array}{l}\text { Based on } 2015 \text { private health insurance reimbursement figures. Note: The Australian } \\
\text { Public Hospital Cost Report } 2013 \text { [46] cites } \$ 967.29 \text { per night government. The figure used } \\
\text { in this study was considered conservative. }\end{array}$ \\
\hline Day Hospital, per visit & $\$ 255.15$ & Based on The Australian Public Hospital Cost Report 2013 [46] (clinic code 40.12, pg 112). \\
\hline Private physiotherapy clinic visit & $\$ 74.90$ & $\begin{array}{l}\text { Based on COMCARE } 2015 \text { [47] rates for a standard consultation or return visit. Same charge } \\
\text { was applied regardless of group-based on one-to-one based care. }\end{array}$ \\
\hline Domiciliary (hospital in the home) visit & $\$ 87.10$ & COMCARE 2015 [47] rate for a standard visit was used. \\
\hline Physiotherapy supervised hydrotherapy visit & $\$ 74.90$ & $\begin{array}{l}\text { Based on COMCARE } 2015 \text { [47] rates. Same charge was applied regardless of group-based or } \\
\text { one-to-one based care. }\end{array}$ \\
\hline
\end{tabular}

Key: All charges in Australian dollars 
comorbidity (any condition of the cardiovascular, renal, respiratory, endocrine, liver, central and peripheral nervous systems, and excluding musculoskeletal conditions), other lower limb or back problems limiting mobility, surgical approach ('anterior' or 'other'), and education level (Yr 8 or below, Yrs 9-10, Yrs 11-12, Degree qualified). We also included any measured variable that was found to be significantly different between the treatment groups prior to matching. For this reason, employment status was also used for matching.

ii) We assessed the distribution of the PSs across the two treatment groups using visual inspection and descriptive statistics to ensure there was sufficient overlap (area of common support [33-35]) in probabilities to receive inpatient rehabilitation.

iii) Using caliper matching without replacement $[32,33]$ we then used the PSs to match each patient who received inpatient rehabilitation in a 1:1 ratio with one who did not. A caliper distance of an absolute difference in PS of 0.05 was employed, equating to 0.28 of the pooled SD of the PSs for the unmatched cohorts. Successful matching was indicated by achieving a standardized mean difference (SMD) [34] between the groups $<0.20$ for any given variable (differences $<0.1$ are considered negligible [36]; differences up to 0.25 are considered tolerable [35]), and an absence of statistical significant difference $(p<0.05)$.

Variables not included in the matching were 'hospital' and 'surgeon'. The inclusion of these caused non-convergence of the estimate in the PS calculation owing to high correlation between surgeon or hospital and treatment group. To assess the influence of 'hospital' or 'surgeon' on primary outcomes, we performed multivariable linear regression analyses incorporating these variables.

As treatment allocation was not random, we considered the experience of a second arthroplasty (different joint) or later joint-related complication after 90 days as a potential between-group confounder of the primary outcomes. Thus, we conducted sensitivity analyses on the 365-day outcomes excluding persons who experienced such events.

We also performed sensitivity analysis using Rosenbaum bounds $[37,38]$ on the matched groups to determine the possible effect of unmeasured confounders on the conclusiveness of our results. A sensitivity parameter 'Gamma' was defined in the Rosenbaum bounds analysis. The Gamma indirectly informs how large the effect of the unmeasured confounder would need to be to change the conclusiveness of the matched results. The larger the gamma the more robust the result to an unobserved confounder. A Gamma of 1.2, for example, indicates that an unmeasured confounder would need to increase the likelihood of a patient being assigned to the inpatient group by a factor of 1.2 before the conclusiveness of the results are threatened [36, 44].
All analyses were conducted using SAS V9.4 (SAS Institute Inc. Cary, NC, USA) and the psens function in the rbounds package of R. No imputation was undertaken for missing data.

\section{Results}

Figure 1 summarizes cohort ascertainment. From an eligible sample of 431 privately insured primary, unilateral THA patients from 12 hospitals, 123 pairs were matched.

\section{Unmatched cohort}

In the unmatched cohort, a PS was estimable for 403 patients. The mean (SD) propensity score for the sample was 0.34 (0.18). Assessment of the overlap of the PSs across the unmatched groups revealed sufficient common support between the two treatment groups [Inpatient Group, $n=136$ - mean 0.44 (0.18), min 0.06, $\max 0.85$; Non-inpatient Group, $n=267$ - mean 0.29 (0.16), min 0.02, $\max 0.85]$.

\section{Unmatched versus matched cohorts}

In the unmatched cohort, the inpatient rehabilitation group was older, had more males, had higher levels of comorbidity, and worse baseline OHSs (Table 2). Unadjusted comparisons between the two groups revealed significantly worse health scores at every time point and worse OHS at 90 days for the Inpatient Group (Additional file 1). Matching lowered the SMD for all but one covariate (it went from 0.10 to 0.11); the largest SMD was 0.14 (Table 3). Acute-care LOS was significantly longer in the Inpatient Group in both the unmatched (6.2 (2.2) vs 4.6 (1.7) days) and matched (5.9 (2.1) vs 5.0 (2.0) days) conditions.

\section{Outcomes - Matched cohort only}

35- and 90-days: Table 4 summarizes the comparisons between the matched groups. The Inpatient Group did not have superior outcomes at 35- or 90-days. Time-off-work outcomes were not significantly different. Median rehabilitation provider charges were significantly higher in the Inpatient Group regardless of whether inpatient provider charges were included in the calculation. The Inpatient Group received a greater number of physiotherapy sessions in the community (day hospital as well as clinic) [median difference 5 (IQR 9,0); Inpatient Group - 6 (IQR 2,10), Non-Inpatient Group 0 (IQR 0,3)] (Table 5). A greater proportion of the Inpatient Group were receiving community-based rehabilitation beyond week $10(23.9 \%$ [95\%CI $17.1-32.4]$ vs $12.2 \%[7.2-20.2])$.

365-days: The Inpatient Group did not have superior outcomes at 365 days; the median OHS in both groups was the maximum score possible (48). Sensitivity analyses for the 365-day outcomes involving 114 pairs, 


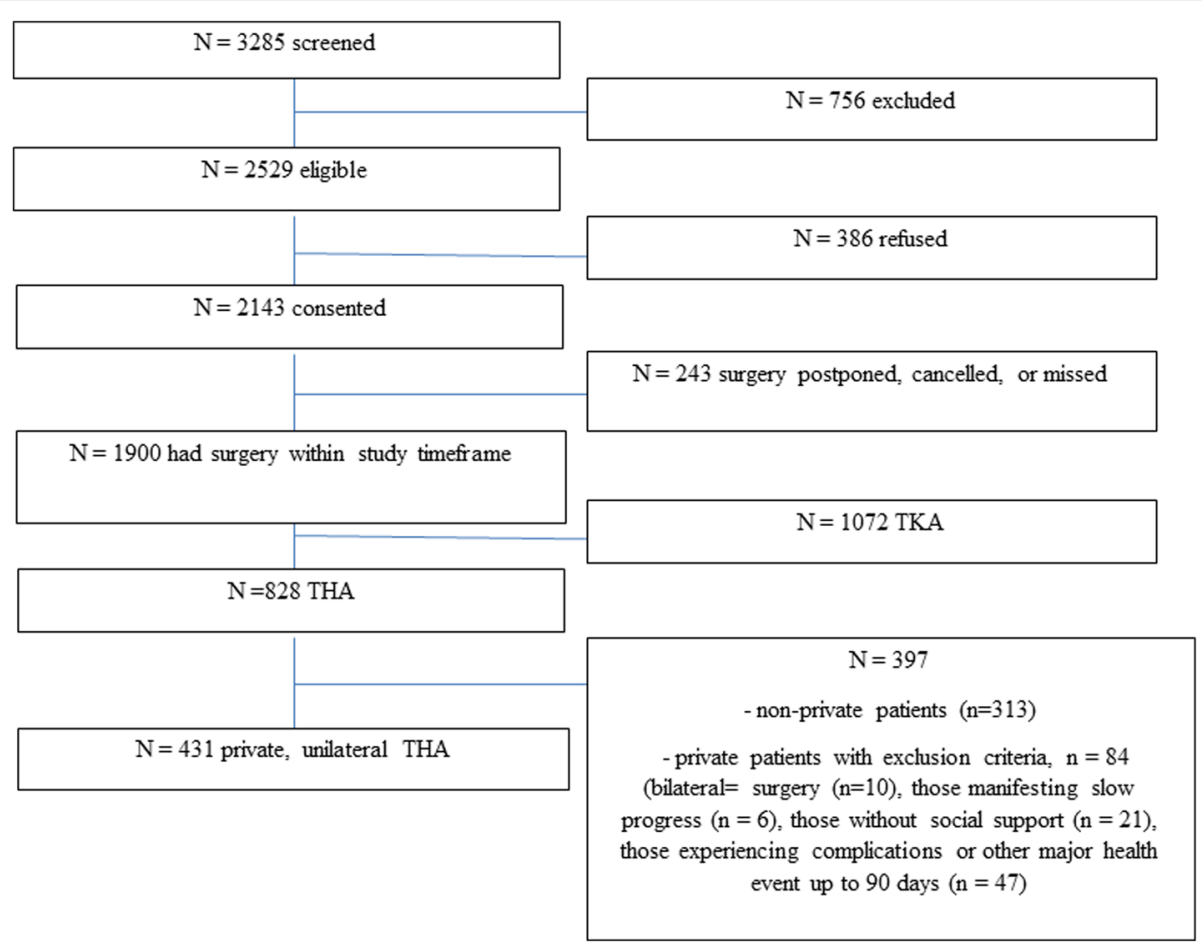

Fig. 1 Cohort ascertainment

yielded the same results (Additional file 2). In the analyses incorporating hospital and surgeon, neither significantly influenced the primary outcomes at any point (Additional file 3). Sensitivity analysis exploring the Rosenbaum bounds for the possible effect of unmeasured confounders yielded gamma values from 1.1 to 6.0 (Additional file 4).

\section{Discussion}

Results from a related PS matched cohort involving uncomplicated TKA recipients indicated that the inpatient rehabilitation pathway, compared to the non-inpatient pathway, did not provide superior patient-reported outcomes up to 1-year post-surgery [32]. The current study suggests the same is true for THA recipients. Importantly, the median between-group differences for the OHS and EQVAS were much smaller than the differences estimated to be clinically important. Further, the inpatient rehabilitation pathway was associated with far higher rehabilitation provider charges, and similar time-off -work outcomes for patients and carers. Overall, our findings align with the one aforementioned RCT conducted in this area involving hip arthroplasty [25], and highlight the impressive levels of patient-reported recovery typically seen after this surgery regardless of the rehabilitation pathway taken.

Our study has several strengths. The use of propensity-based scoring has allowed us to report the comparison between two rehabilitation pathways in simple, absolute terms of the outcomes whilst keeping measured covariates balanced between the groups. Most importantly, acceptable matching across all our measured covariates was achieved indicating that any differences in the outcomes observed are not attributable to confounding resulting from differences in these variables. Further, we removed other sources of 'noise' through our strict eligibility criteria, thus, between-group differences in the rate of complications or other major health events are not a source of bias. Finally, our cohort was derived nationally, thus, the characteristics of the unmatched and matched samples should reasonably reflect private patients who undergo THA in Australia.

Despite its advantages, a limitation of the PS method is that bias from unmeasured covariates that may be influencing treatment allocation or outcomes is not eliminated [33-37]. Here, surgeons and hospitals could be viewed as possible confounders. Our supplementary regression analyses, however, allowed us to adjust for the effect of these with neither having a significant effect on outcomes. We did not match on prosthesis type (as there were too many), though we did adjust for what may be considered more important (surgical approach). There is still a possibility that we have not accounted for all unknown confounders, but we think it unlikely we missed important ones. Our sensitivity analyses on the possible effect of unmeasured confounders indicate that an unknown confounder would need to change the 
Table 2 Characteristics of total hip arthroplasty recipients: Pre-matching

\begin{tabular}{|c|c|c|c|c|}
\hline & $\begin{array}{l}\text { Inpatient Rehabilitation } \\
\text { Group, } n=141\end{array}$ & $\begin{array}{l}\text { No Inpatient Rehabilitation } \\
\text { Group, } n=290\end{array}$ & $\begin{array}{l}\text { Standardized Mean } \\
\text { Difference }\end{array}$ & $P$-value \\
\hline Age, mean (SD), y & $68.7(9.9)$ & $63.7(10.4)$ & 0.50 & $<0.001$ \\
\hline Male, \% (n) & $68.1(96)$ & 47.6 (138) & 0.42 & $<0.001$ \\
\hline BMI, mean (SD) & $27.7(4.9)$ & $28.2(4.9)$ & 0.11 & 0.27 \\
\hline \multicolumn{5}{|l|}{ Education, \% (n) } \\
\hline 1 & $1.4(2)$ & $1.4(4)$ & 0.0 & 0.97 \\
\hline 2 & $21.3(30)$ & $18.3(53)$ & 0.08 & 0.46 \\
\hline 3 & $56.7(80)$ & $51.4(149)$ & 0.11 & 0.30 \\
\hline 4 & $20.6(29)$ & $29.0(84)$ & 0.20 & 0.06 \\
\hline \multicolumn{5}{|l|}{ ASA, \% (n) } \\
\hline 1 & $9.2(13)$ & $19.1(55)$ & 0.29 & 0.009 \\
\hline 2 & $54.6(77)$ & $62.2(180)$ & 0.15 & 0.14 \\
\hline 3 & $33.3(47)$ & $17.4(50)$ & 0.37 & $<0.001$ \\
\hline 4 & $2.8(4)$ & $1.4(4)$ & 0.10 & 0.30 \\
\hline \multicolumn{5}{|l|}{ Comorbidity, \% (n) } \\
\hline Nil & $8.5(12)$ & $21.7(63)$ & 0.38 & $<0.001$ \\
\hline Yes, but no daily medication & $5.0(7)$ & $11.4(33)$ & 0.24 & 0.03 \\
\hline Yes, with daily medication & $86.5(122)$ & $66.9(194)$ & 0.48 & $<0.001$ \\
\hline Oxford Hip Score, mean (SD) & $22.3(9.2)$ & $24.4(8.6)$ & 0.24 & 0.02 \\
\hline EuroQol VAS, mean (SD) & $71.4(19.0)$ & $73.5(16.3)$ & 0.12 & 0.24 \\
\hline Other lower limb or back problems limiting mobility, \% (n) & $51.1(72)$ & $42.1(122)$ & 0.18 & 0.08 \\
\hline Anterior surgical approach & $33.8(48)$ & $31.0(90)$ & 0.06 & 0.56 \\
\hline Paid employment, \% (n) & $31.2(44)$ & $44.1(128)$ & 0.27 & 0.01 \\
\hline
\end{tabular}

Abbreviations: BMI body mass index, ASA American Society of Anesthesiology, Education $1=$ nil formal; $2=$ Year 10 or less; $3=$ Year 11 or $12 ; 4=$ Degree or greater; Comorbidity included any conditions of the cardiovascular, renal, respiratory, endocrine, liver, central and peripheral nervous systems, and excluding other musculoskeletal conditions. Note: Standardized mean difference was calculated using the following equation - Standardized Mean Difference ${ }^{34}=\left(\right.$ Mean $1-M^{2}$ Mean 2$) / \sqrt{ }\left((\mathrm{SD} 1)^{2}+(\mathrm{SD} 2)^{2}\right) / 2$

probability of being allocated to inpatient rehabilitation by at least a factor of 1.3 for five of our outcomes in order to change the statistical significance of the results. Further, if an unmeasured confounder changed a result from non-significant to significant, the effect could still favor discharge directly home. Given we have included many of the known potential confounders in our PS analysis and supplemented this with multiple regressions including 'surgeon' and 'hospital', we contend the important variables are covered. Further, we are not aware of any other unmeasured confounder that the literature points to that would lead us to change our conclusions. That our results concord with the one RCT conducted in this area [25] and several observational studies [28-30], it would appear we have not overlooked major confounding influences.

A potential limitation of our study is the lack of physical performance measures [45]. It remains to be seen if inpatient rehabilitation improves gait or strength more so than rehabilitation provided in other settings. We note gait outcomes have not been shown to be superior in supervised community-based settings compared to home programs when conducted within 8-weeks of surgery $[10,17]$. It is possible the same is true for inpatient rehabilitation.

An important caveat is that our results apply to those who have had an uncomplicated recovery and to those for whom discharge destination was a choice. We contend then that the inpatient rehabilitation pathway remains an important option for those with complications, limited social supports, and poor progress acutely. Based on the criteria used here, we estimate that a small minority (approximately 14\%) of privately insured patients may require inpatient rehabilitation based on these three conditions (9.1, 4.1 and $1.2 \%$ respectively) (Fig. 1). We note, however, recent data from the US suggest discharge to inpatient rehabilitation facilities following THA is associated with increased morbidity [23]. A reasonable approach, therefore, would be to avoid referral to inpatient facilities unless alternatives are exhausted.

A final important caveat is that our cost data pertain only to the first 90 days after surgery and only include rehabilitation provider charges. It is likely that there were continued cost differences beyond this time given a 
Table 3 Characteristics of total hip arthroplasty recipients: Post-matching

\begin{tabular}{|c|c|c|c|c|}
\hline & $\begin{array}{l}\text { Inpatient Rehabilitation } \\
\text { Group, } n=123\end{array}$ & $\begin{array}{l}\text { No Inpatient Rehabilitation } \\
\text { Group, } n=123\end{array}$ & $\begin{array}{l}\text { Standardized Mean } \\
\text { Difference }\end{array}$ & $P$-value \\
\hline Age, mean (SD), y & $67.8(10.0)$ & $66.9(10.6)$ & 0.09 & 0.48 \\
\hline Male, \% (n) & 64.2 & 68.3 & 0.09 & 0.50 \\
\hline BMI, mean (SD) & $27.8(4.8)$ & $28.0(5.1)$ & 0.04 & 0.76 \\
\hline \multicolumn{5}{|l|}{ Education, \% (n) } \\
\hline 1 & $1.6(2)$ & $1.6(2)$ & 0 & 1.0 \\
\hline 2 & $20.3(25)$ & $22.80(28)$ & 0.06 & 0.64 \\
\hline 3 & $55.3(68)$ & $51.2(63)$ & 0.08 & 0.52 \\
\hline 4 & $22.8(28)$ & $24.4(30)$ & 0.04 & 0.76 \\
\hline \multicolumn{5}{|l|}{$\mathrm{ASA}, \%(\mathrm{n})$} \\
\hline 1 & $10.6(13)$ & $7.3(9)$ & 0.11 & 0.37 \\
\hline 2 & $59.4(73)$ & $61.0(75)$ & 0.03 & 0.79 \\
\hline 3 & $28.5(35)$ & $28.5(35)$ & 0.0 & 1.0 \\
\hline 4 & $1.6(2)$ & $3.3(4)$ & 0.11 & 0.70 \\
\hline \multicolumn{5}{|l|}{ Comorbidity, \% (n) } \\
\hline $\mathrm{Nil}$ & $8.9(11)$ & $8.9(11)$ & 0 & 1.0 \\
\hline Yes, but no daily medication & $4.9(6)$ & $3.3(4)$ & 0.08 & 0.52 \\
\hline Yes, with daily medication & $86.2(106)$ & $87.8(108)$ & 0.05 & 0.71 \\
\hline Oxford Hip Score, mean (SD) & $23.1(8.9)$ & $21.9(8.2)$ & 0.14 & 0.27 \\
\hline EuroQol VAS, mean (SD) & $71.7(19.4)$ & $70.8(16.8)$ & 0.05 & 0.69 \\
\hline Other lower limb or back problems limiting mobility, \% (n) & $47.2(58)$ & $48.8(60)$ & 0.03 & 0.80 \\
\hline Anterior surgical approach & $33.8(42)$ & $31.0(38)$ & 0.06 & 0.56 \\
\hline Paid employment, No. (\%) & $34.2(42)$ & $31.7(39)$ & 0.05 & 0.68 \\
\hline
\end{tabular}

Abbreviations: BMI body mass index, ASA American Society of Anesthesiology; Education $1=$ nil formal; $2=$ Year 10 or less; $3=$ Year 11 or $12 ; 4=$ Degree or greater; Comorbidity included any conditions of the cardiovascular, renal, respiratory, endocrine, liver, central and peripheral nervous systems, and excluding other musculoskeletal conditions Note: Standardized mean difference was calculated using the following equation - Standardized Mean Difference ${ }^{34}=\left(\right.$ Mean $1-$ Mean 2) $/ \sqrt{ }\left((\text { SD1 })^{2}+(\text { SD2 })^{2}\right) / 2$

Table 4 Outcomes at 35, 90 and 365 days in the matched cohorts

\begin{tabular}{|c|c|c|c|c|c|c|c|c|c|c|c|c|}
\hline & \multicolumn{4}{|l|}{35 days } & \multicolumn{4}{|l|}{90 days } & \multicolumn{4}{|l|}{365 days } \\
\hline & Inpatient & $\begin{array}{l}\text { No } \\
\text { Inpatient }\end{array}$ & $P$-value & $\begin{array}{l}\text { Median } \\
\text { difference }\end{array}$ & Inpatient & $\begin{array}{l}\text { No } \\
\text { Inpatient }\end{array}$ & $P$-value & $\begin{array}{l}\text { Median } \\
\text { difference }\end{array}$ & Inpatient & $\begin{array}{l}\text { No } \\
\text { Inpatient }\end{array}$ & $P$-value & $\begin{array}{l}\text { Median } \\
\text { difference }\end{array}$ \\
\hline $\begin{array}{l}\text { OHS median } \\
\text { (IQR) }\end{array}$ & & & & & $46(41,48$ & $46(41,48)$ & 0.60 & $0(-3,3)$ & $48(46,48)$ & $48(46,48)$ & 0.91 & $0(-1,1)$ \\
\hline $\begin{array}{l}\text { EQVAS today, } \\
\text { median (IQR) }\end{array}$ & $\begin{array}{l}80 \\
(75,90)\end{array}$ & $\begin{array}{l}85 \\
(80,90)\end{array}$ & 0.24 & $\begin{array}{l}0 \\
(-10,12)\end{array}$ & $\begin{array}{l}85 \\
(80,95)\end{array}$ & $\begin{array}{l}90 \\
(80,95)\end{array}$ & 0.49 & $\begin{array}{l}0 \\
(-10,10)\end{array}$ & $\begin{array}{l}85 \\
(75,95)\end{array}$ & $\begin{array}{l}90 \\
(80,95)\end{array}$ & 0.09 & $\begin{array}{l}5 \\
(-10,15)\end{array}$ \\
\hline $\begin{array}{l}\text { Rehabilitation } \\
\text { costs, \$, } \\
\text { median (IQR) }\end{array}$ & & & & & $\begin{array}{l}7620 \\
(5796 \\
10,399)\end{array}$ & $0(0,225)$ & $<0.001$ & $\begin{array}{l}-\$ 7582 \\
(-10,249 \\
-5649)\end{array}$ & & & & \\
\hline $\begin{array}{l}\text { Rehabilitation } \\
\text { costs, \$, excluding } \\
\text { inpatient costs }\end{array}$ & & & & & $\begin{array}{l}\$ 824 \\
(87,2041)\end{array}$ & $0(0,225)$ & $<0.001$ & $\begin{array}{l}-\$ 749 \\
(-1786,0)\end{array}$ & & & & \\
\hline $\begin{array}{l}\text { Time off paid } \\
\text { employment } \\
>6 \text { weeks, } \%(95 \% \text { Cl) }\end{array}$ & & & & & $24(17,32)$ & $21(15,30)$ & 0.66 & $-2(-13,8)$ & & & & \\
\hline $\begin{array}{l}\text { Carer time off paid } \\
\text { employment, } \\
\text { Yes/No, \% (95\%Cl) }\end{array}$ & $13(8,21)$ & $13(8,21)$ & 1.0 & $0(-8,8)$ & & & & & & & & \\
\hline
\end{tabular}


Table 5 Profile of community-based supervised rehabilitation received amongst those who received it

\begin{tabular}{|c|c|c|c|c|c|c|}
\hline & \multicolumn{3}{|c|}{ Inpatient Group } & \multicolumn{3}{|c|}{ No Inpatient Group } \\
\hline & $\%$ & No. of visits, mean (sd) & Median & $\%$ & No. of visits, mean (sd) & Median \\
\hline Receiving community rehabilitation & 79 & $8.7(4.5)$ & 8 & 35 & $5.4(3.7)$ & 5 \\
\hline \multicolumn{7}{|l|}{ Type of community-based rehabilitation } \\
\hline 1-to-1 clinic & 36 & $5.6(4.4)$ & 5 & 37 & $3.7(2.4)$ & 3 \\
\hline 1-to-1 hydrotherapy & 11 & $6.2(3.2)$ & 7 & 11 & $3.3(1.3)$ & 3 \\
\hline Group-based clinic & 13 & $6.3(2.9)$ & 5 & 11 & $5.0(3.6)$ & 6 \\
\hline Group-based hydrotherapy & 6 & $5.3(3.8)$ & 4 & 9 & $4.5(2.6)$ & 4 \\
\hline Domiciliary & 1 & 1 & 1 & 40 & $6.2(3.6)$ & 7 \\
\hline Day Hospital program & 62 & $8.7(3.8)$ & 8 & 6 & $7.0(1.4)$ & 7 \\
\hline
\end{tabular}

Note: The data summarise attendance of those who had ongoing supervised rehabilitation after the acute hospital. Those who did not have ongoing supervised rehabilitation after discharge from hospital are excluded from these calculations. Interpretation example $-62 \%$ of those who had ongoing supervised rehabilitation after discharge from inpatient rehabilitation participated in a Day Hospital program compared to $6 \%$ of those who did not participate in inpatient rehabilitation. The percentages under 'type' are not additive as each type is not mutually exclusive

greater proportion of the Inpatient Group were still receiving community-based therapy beyond 10 weeks.

\section{Conclusions}

In conclusion, in the absence of sufficient high-level evidence to date, our study provides robust and useful signals concerning the comparative effectiveness and provider charges of a pathway that includes inpatient rehabilitation after uncomplicated THA. Consistent with the one published RCT in this space [25], our data indicate a rehabilitation pathway incorporating inpatient rehabilitation is not likely to be cost-effective for uncomplicated THA recipients. Our data and data elsewhere support the use of community-based and home-based programs to secure impressive levels of patient-reported recovery.

\section{Additional files}

Additional file 1: Unadjusted analyses. Unadjusted analysis between treatment group and outcome. (DOCX $20 \mathrm{~kb})$

Additional file 2: Sensitivity analysis 1. Sensitivity analysis for 365 day outcomes. (DOCX $19 \mathrm{~kb}$ )

Additional file 3: Sensitivity analysis 2. Sensitivity analysis to determine effect of 'hospital' and 'surgeon'. (DOCX $39 \mathrm{~kb}$ )

Additional file 4: Sensitivity analysis 3. Sensitivity analysis to determine effect of the unmeasured confounders. (DOCX $21 \mathrm{~kb}$ )

\section{Abbreviations}

95\%Cl: 95\% confidence interval; AOANJRR: Australian Orthopaedic Association National Joint Replacement Registry; ASA: American Society of Anesthesiologists; AUD: Australian dollars; EQVAS: EuroQol Visual Analogue Scale; LOS: Length of stay; OHS: Oxford Hip Score; PS: Propensity score; RCT: Randomized controlled trial; SD: Standard deviation; SMD: Standardized mean difference; THA: Total hip arthroplasty; TKA: Total knee arthroplasty; UK: United Kingdom; US: United States; yr: Year

\section{Acknowledgements}

Project manager - Helen Badge. Data entry - Shirley Cross, Carolyn GrayRobens, Kristen Kovacic. Patients and hospitals participating in the study.

\section{Funding}

The study was funded by the HCF Research Foundation The funder did not have any influence on the study aims, design, analysis or write-up.

\section{Availability of data and materials}

This study was not publicly funded. The data used in this study are available in an excel file from the corresponding author upon reasonable request.

\section{Authors' contributions}

JMN - study conception, design, data collection, data collation, analysis, manuscript draft, final manuscript, obtainment of funding, supervision of contributors. RM - supervision of contributors, data collation, manuscript draft, approval of final manuscript. $\mathrm{AH}$ - data collection, data collation, analysis, manuscript draft, approval of final manuscript. IAH - manuscript draft, final manuscript, obtainment of funding, supervision of contributors. WX - analysis, manuscript draft, final manuscript, obtainment of funding. All authors read and approved the final manuscript.

\author{
Authors' information \\ JMN - PhD, BAppSc (Phty). \\ $\mathrm{AH}-\mathrm{MBBS}$. \\ RM - PhD, MBBS, MMed (Clin Epi). \\ IAH - PhD, MMed (Clin Epi), MBBS, FRACS (Orth). \\ $W X-P h D$
}

Ethics approval and consent to participate

Ethical approval was provided by all Hunter New England HREC (NSW), LNR/12/ HNE/390; St Vincent's Health and Aged Care HREC (Queensland), HREC \#13/10; Austin Health HREC (Victoria),LNR/14/Austin/208 LNRR MAP; Barwon Health HREC (Victoria), 13/82; Epworth HREC (Victoria), LR138-13; Calvary Health Care Clinical and Research Ethics Committee (Tasmania), 2:05:13 and 5:13:12, and; Calvary Healthcare Adelaide HREC (South Australia), 13-CHREC-E007. Informed written consent was obtained from all patients.

Consent for publication

Not applicable.

\section{Competing interests}

The authors declare that they have no competing interests.

\section{Publisher's Note}

Springer Nature remains neutral with regard to jurisdictional claims in published maps and institutional affiliations.

\section{Author details}

${ }^{1}$ South Western Sydney Clinical School, University of New South Wales, Liverpool Hospital, Elizabeth Drive, Liverpool, NSW 2170, Australia. ${ }^{2}$ South West Sydney Local Health District, Locked Bag 7103, Liverpool, NSW 2170, 
Australia. ${ }^{3}$ Ingham Institute of Applied Medical Research, Westfields Liverpool, PO Box 3151, Liverpool, NSW 2170, Australia.

\section{Received: 9 March 2018 Accepted: 14 June 2018 Published online: 18 July 2018}

\section{References}

1. Learmonth ID, Young C, Rorabeck C. The operation of the century: total hip replacement. Lancet. 2007;370(9597):1508-19.

2. Vissers MM, Bussmann JB, de Groot IB, Verhaar JAN, Reijman M. Physical functioning four years after total hip or knee arthroplasty. Gait Posture. 2013;38:310-5

3. Naylor JM, Harmer AR, Heard RC, Harris IA. Patterns of recovery following knee and hip replacement in an Australian cohort. Aust Health Rev. 2009;33: 124-35.

4. Ng CY, Ballantyne JA, Brenkel IJ. Quality of life and functional outcome after primary total hip replacement. A five-year follow-up. J Bone Joint Surg Br. 2007;89:868-73.

5. Yuasa T, Maezawa K, Nozawa M, Kaneko K. Cementless total hip arthroplasty for patients with rheumatoid arthritis: a more than 10-year follow-up. Eur J Orthop Surg Traumatol. 2016;26:599-603.

6. Colo E, Rijnen WH, Gardeniers JW, van Kampen A, Schreurs BW. Satisfying results of primary hip arthroplasty in patients with hip dysplasia at a mean follow-up of 20 years. Clin Orthop Relat Res. 2016;474:2462-8.

7. National Joint Replacement Registry. Analysis of State and Territory Health Data. All Arthroplasty. Supplementary Report 2017. Adelaide: AOA; 2017.

8. National Joint Registry. 14th Annual Report 2017. http://www.njrreports.org. uk/Portals/0/PDFdownloads/NJR\%2014th\%20Annual\%20Report\%202017.pdf. Accessed 3 July 2018.

9. Kurtz S, Ong K, Lau E, Mowat F, Halpern M. Projections of primary and revision hip and knee arthroplasty in the United States from 2005 to 2030. J Bone Joint Surg Am. 2007:89:780e5.

10. Coulter CL, Scarvell JM, Neeman TM, Smith PN. Physiotherapist directed rehabilitation exercises in the outpatient or home setting improve strength, gait speed, and cadence after elective total hip replacement: a systematic review. J Physiother. 2013;59:219-26.

11. Kramer JF, Speechley M, Bourne M, Rorabeck C. Comparison of clinic- and home-based rehabilitation programs after total knee arthroplasty. Clin Orthop Relat Res. 2003:410:225-34.

12. Mockford BJ, Thompson NW, Humphreys P, Beverland DE. Does a standard outpatient physiotherapy regime improve the range of knee motion after primary total knee arthroplasty? J Arthroplast. 2008;23:1110-4.

13. Han ASY, Nairn L, Harmer AR, Crosbie J, March L, Parker D, et al. Early rehabilitation after total knee replacement surgery: a multicenter, noninferiority, randomized clinical trial comparing a home exercise program with usual outpatient care. Arth Car Res. 2015;67:196-202.

14. Russell TG, Buttrum P, Wootton R, Jull GA. Internet-based outpatient telerehabilitation for patients following total knee arthroplasty: a randomized controlled trial. J Bone Joint Surg Am. 2011;93:113-20.

15. Ko V, Naylor J, Harris I, Crosbie J, Yeo A, Mittal R. One-to-one therapy is not superior to group or home-based therapy after total knee arthroplasty: a randomized, superiority trial. J Bone Joint Surg Am. 2013;95:1942-9.

16. Austin MS, Urbani BT, Fleischman AN, Fernando ND, Purtill JJ, Hozack WJ, et al. Formal physical therapy after total hip arthroplasty is not required: a randomized controlled trial. J Bone Joint Surg Am. 2017;99:648-55.

17. Coulter C, Perriman DM, Neeman TM, Smith PN, Scarvell JM. Supervised or unsupervised rehabilitation after total hip replacement provides similar improvements for patients: a randomised controlled trial. Arch Phys Med Rehabil. 2017;98:2253-64. https://doi.org/10.1016/j.apmr.2017.03.032

18. Bozic KJ, Ward L, Vail TP, Maze M. Bundled payments in total joint arthroplasty: targeting opportunities for quality improvement and cost reduction. Clin Orth Rel Res. 2014;472:188-93.

19. Soderstrom $L$, Tousignant $P$, Kaufman $T$. The health and cost effects of substituting home care for inpatient acute care: a review of the evidence. Can Med Ass J. 1999:160:1151-5.

20. Krummenauer $F$. The incremental cost effectiveness of in-patient versus outpatient rehabilitation after total hip arthroplasty. Results of a pilot investigation. Eur J Med Res. 2008;13:267-74.

21. RACS Surgical Practical Variation Report - Orthopaedic procedures. https:// surgeons.org/news/surgical-variance-reports/. Accessed 3 July 2018.
22. Hart A, Bergeron SG, Epure L, Huk O, Zukor D, Antoniou J. Comparison of US and Canadian perioperative outcomes and hospital efficiency after total hip and knee arthroplasty. JAMA Surg. 2015;150:990-8.

23. Fu MC, Samuel AM, Sculco PK, MacLean CH, Padgett DE, McLawhorn AS Discharge to inpatient facilities after total hip arthroplasty is associated with increased postdischarge morbidity. J Arthroplast. 2017:32:S144-9.

24. Waddell J, Johnson K, Hein W, Raabe J, Fitzgerald G, Turibio F. Orthopedic practice in total hip arthroplasty and total knee arthroplasty: results from the global Orthopaedic registry (GLORY). Am J Orthop. 2010;39(9 Suppl):5-13.

25. Mahomed NN, Davis AM, Hawker G, Badley E, Davey JR, Syed KA, et al. Inpatient compared with home-based rehabilitation following primary unilateral total hip or knee replacement: a randomized controlled trial. J Bone Joint Surg Am. 2008;90:1673-80.

26. Buhagiar MA, Naylor JM, Simpson G, Harris IA, Kohler F. Understanding consumer and clinician preferences and decision making for rehabilitation following arthroplasty in the private sector. BMC Health Serv Res. 2017;17(1): 415. https://doi.org/10.1186/s12913-017-2379-9.

27. Zuckerman JD. Inpatient rehabilitation after total joint replacement. JAMA. 1998;279:880.

28. Cushner F, Agnelli G, Fitzgerald G, Warwick D. Complications and functional outcomes after total hip arthroplasty and total knee arthroplasty: results from the global Orthopaedic registry (GLORY). Am J Orthop. 2010;39(9 Suppl):22-8.

29. Benz T, Angst F, Oesch P, Hilfiker R, Lehmann S, Mueller Mebes C, et al. Comparison of patients in three different rehabilitation settings after knee or hip arthroplasty: a natural observational, prospective study. BMC Musculoskel Dis. 2015;16:317.

30. Tribe KL, Lapsley HM, Cross MJ, Courtenay BG, Brooks PM, March LM. Selection of patients for inpatient rehabilitation or direct home discharge following total joint replacement surgery: a comparison of health status and out-of-pocket expenditure of patients undergoing hip and knee arthroplasty for osteoarthritis. Chronic IIIness. 2005;1:289-302.

31. Chua M, Hart A, Harris IA, Mittal R, Xuan W, Naylor JM. Early mobilisation after total hip or knee arthroplasty: a multicentre prospective observational study. PLoS One. 2017;12(6):e0179820. https://doi.org/10.1371/journal.pone.0179820

32. Naylor JM, Hart A, Mittal R, Harris IA, Xuan W. The value of inpatient rehabilitation after uncomplicated total knee arthroplasty: a propensity score analysis. Med J Aust. 2017;207:250-5.

33. Austin PC. Balance diagnostics for comparing the distribution of baseline covariates between treatment groups in propensity-score matched samples. Stat Med. 2009;28:3083-107.

34. D'Agostino RB. Tutorial in biostatistics. Propensity score methods for bias reduction in the comparison of a treatment to a non-randomized control group. Stat Med. 1998;17:2265-81.

35. Stuart EA, Lee BK, Leacy FP. Prognostic score-based balance measures for propensity score methods in comparative effectiveness research. J Clin Epidemiol. 2013;66:S84-90.

36. Haukoos JS, Lewis RJ. The propensity score. JAMA. 2015:314:1637-8

37. Caliendo M, Kopeinig S. Some practical guidance for the implementation of propensity score matching. IZA Discussion Paper No. 1588, 2005. http://ftp. iza.org/dp1588.pdf. Accessed 3 July 2018.

38. Rosenbaum PR. Sensitivity analysis in observational studies. In: Everitt BS, Howell DC, editors. Encyclopaedia of statistics in behavioral science. Chichester: Wiley; 2005.

39. Naylor JM, Descallar J, Grootemaat M, Badge H, Harris IA, Simpson G, et al. Is satisfaction with the acute-care experience higher amongst consumers treated in the private sector? A survey of public and private sector arthroplasty recipients. PLoS One. 2016;11(8):e0159799. https://doi.org/10. 1371/ journal.pone.0159799 23.

40. Clavien PA, Barkun J, de Oliveira ML, Vauthey JN, Dindo D, Schulick RD, et al. The Clavien-Dindo classification of surgical complications. Ann Surg. 2009;250:187-96.

41. Beard DJ, Harris K, Dawson J, Doll H, Murray DW, Carr AJ, et al. Meaningful changes for the Oxford hip and knee scores after joint replacement surgery. J Clin Epidemiol. 2015;68:73-9.

42. Chatterii R, Naylor JM, Harris IA, Armstrong E, Davidson E, Ekmejian R, et al. An equivalence study: are patient-completed and telephone interview equivalent modes of administration for the EuroQol survey. Health Qual Life Outcomes. 2017;15(1):18. https://doi.org/10.1186/s12955-017-0596-x.

43. Paulsen A, Roos E, Pedersen A, Overgaard S. Minimal clinically important improvement (MCII) and patient acceptable symptom state (PASS) in total hip arthroplasty (THA) patients 1 year postoperatively. Acta Orthop. 2014; 85:39-48. 
44. Keele L. 2010 http://www.personal.psu.edu/ljk20/rbounds\%20vignette.pdf. Accessed 3 July 2018.

45. Wijnen A, Bouma SE, Seeber GH, van der Woude LHV, Bulstra SK, Lazovic D, et al. The therapeutic validity and effectiveness of physiotherapeutic exercise following total hip arthroplasty for osteoarthritis: a systematic review. PLoS One. 2018;13(3):e0194517.

46. Independent Hospital Pricing Authority. National Hospital Cost Data Collection Australian Public Hospitals Cost Report 2012-2013, Round 17. 2013: Australia.

47. Australian Government COMCARE. Allied Health Rates - Physiotherapy NSW - January 2015. 2015. http://www.comcare.gov.au/claims_and_ benefits/benefits_and_entitlements/fees,_rates_and_reimbursements/allied_ health_rates. Accessed 3 July 2018.

Ready to submit your research? Choose BMC and benefit from:

- fast, convenient online submission

- thorough peer review by experienced researchers in your field

- rapid publication on acceptance

- support for research data, including large and complex data types

- gold Open Access which fosters wider collaboration and increased citations

- maximum visibility for your research: over $100 \mathrm{M}$ website views per year

At BMC, research is always in progress.

Learn more biomedcentral.com/submissions 